\title{
VI - OCORRÊNCIA DE DOMÁCIAS EM ESPÉCIES E HÍBRIDOS DA FAMÍLIA VITACEAE*
}

\author{
Myrthes A. Adamoli de Barros ***
}

\section{RESUMO}

Neste trabalho, o último de um plano elaborado para o conhecimento das clomácias em espécies e híbridos da família Vitaceae, apresentamos os estudos feitos em 120 variedades híbriclas IAC-

Deste total, 74revelaram domácias as quais se enquadram nos tipos em "tufo de pêlos" e variaçóes, e "em bolsa", segundo a classificação de CHEVALIER \& CHESNAIS (1941).

O material estudado constou de folhas não herborizadas, vindas do Instituto Agronômico de Campinas - Seção de Viticultura.

As follás ainda frescas e en várias fases do seu desenvolvimento, foram examinadas em ambas as faces, superior e inferior, na junção do pecíolo, anotando-se as particularidades relativas às domácias tais como: aspecto, localização, tamanho, forma, coloração e tamanho dos pêlos, etc. .

Pudemos observar novamente uma pequena variação nas domácias do tipo "em tufo de pêlos", que ora aparecem como "pêlos exparsos", ora como "aglomerado de pêlos" e ainda como "tufo de pêlos" propriamente dito.

As domácias encontrada nos 120 híbridos, estão assim distribuídas:

a) domácias em "tufo de pêlos" e suas variações - 44

b) domácias em "bolsa" - 3

Os pêlos domaciais podem ser claros ou escuros, curtos ou longos, lisos ou crespos, brancos ou esverdeados.

As domácias aparecem na face inferior do limbo, na axila das nervuras de primeira e segunda ordem e na junção das nervuras com o pecíolo. Ocorrem, também, domácias na confluência das nervuras de diversas ordens.

\section{INTRODUÇÃO}

Neste trabalho, o último de uma série, segundo um plano elaborado anteriormente (ADAMOLI DE BARROS, 1963), estamos reunindo os resultados das observações feitas sobre a ocorrência das domácias em mais 120 híbridos da família Vitaceae, híbridos estes vindos da coleção da Seção de Viticultura do Instituto Agronômico de Campinas.

\section{Relação dos novos híbridos estudados}

* Entregue para publicação em 28-12-1977.

* Prof. a Assistente -Doutor do Departamento de Botânica da E.S.A. "Luiz de Queiroz" - USP. 
Segundo a lista recebida do Instituto Agronômico de Campinas Seção de Viticultura, os híbridos estudados são as seguintes:

\begin{tabular}{|c|c|c|c|c|c|}
\hline IAC & $651-1$ & IAC & $903-15$ & IAC & $1120-5$ \\
\hline IAC & $680-67$ & IAC & $903-47$ & IAC & $1394-1$ \\
\hline IAC & $690-3$ & IAC & $904-4$ & IAC & $1394-2$ \\
\hline IAC & $717-1$ & IAC & $904-11$ & IAC & $1394-4$ \\
\hline IAC & $719-7$ & IAC & $911-2$ & IAC & $1394-6$ \\
\hline IAC & $720-1$ & IAC & $915-2$ & IAC & $1394-8$ \\
\hline IAC & $740-1$ & IAC & $918-52$ & IAC & $1394-9$ \\
\hline IAC & $746-3$ & IAC & $931-13$ & IAC & $1394-11$ \\
\hline IAC & $762-8$ & IAC & $960-2$ & IAC & $1394-13$ \\
\hline IAC & $767-1$ & IAC & $960-11$ & IAC & 1394-15 \\
\hline IAC & $768-2$ & IAC & $960-12$ & IAC & $1395-2$ \\
\hline IAC & $772-41$ & & & IAC & $1395-6$ \\
\hline IAC & $803-10$ & & & IAC & $1395-8$ \\
\hline IAC & $804-13$ & & & & \\
\hline IAC & $813-1$ & & & & \\
\hline IAC & $815-28$ & & & & \\
\hline IAC & $822-21$ & & & & \\
\hline IAC & $847-10$ & & & & \\
\hline IAC & $849-26$ & & & & \\
\hline IAC & $853-3$ & & & & \\
\hline IAC & $861-3$ & & & & \\
\hline IAC & $862-10$ & & & & \\
\hline IAC & $866-39$ & & & & \\
\hline IAC & $871-18$ & & & & \\
\hline IAC & $871-41$ & & & & \\
\hline IAC & $877-2$ & & & & \\
\hline
\end{tabular}




\begin{tabular}{|c|c|c|c|c|c|}
\hline IAC & $1395-14$ & IAC & $1402-1$ & IAC & $1402-31$ \\
\hline IAC & $1397-2$ & IAC & $1402-2$ & IAC & $1402-32$ \\
\hline IAC & 1398-3 & IAC & $1402-3$ & IAC & $1402-33$ \\
\hline IAC & 1398-5 & IAC & $1402-4$ & IAC & $1402-34$ \\
\hline IAC & $1398-7$ & IAC & $1402-5$ & IAC & $1403-1$ \\
\hline IAC & $1398-15$ & IAC & $1402-6$ & IAC & $1403-3$ \\
\hline IAC & $1398-16$ & IAC & $1402-7$ & IAC & $1403-5$ \\
\hline IAC & $1398-17$ & IAC & $1402-8$ & IAC & $1403-7$ \\
\hline IAC & $1398-18$ & IAC & $1402-9$ & IAC & $1403-8$ \\
\hline IAC & $1398-25$ & IAC & $1402-11$ & IAC & $1403-10$ \\
\hline IAC & $1398-26$ & IAC & $1402-12$ & IAC & $1403-11$ \\
\hline IAC & $1398-40$ & IAC & $1402-14$ & IAC & $1403-12$ \\
\hline IAC & $1398-41$ & IAC & $1402-15$ & IAC & $1403-13$ \\
\hline IAC & $1398-42$ & IAC & $1402-16$ & IAC & $1403-14$ \\
\hline IAC & 1399-1 & IAC & $1402-17$ & IAC & $1403-15$ \\
\hline IAC & 1399-3 & IAC & $1402-18$ & & \\
\hline IAC & $1399-4$ & IAC & $1402-19$ & & \\
\hline IAC & 1399-5 & IAC & $1402-20$ & & \\
\hline IAC & $1399-6$ & IAC & $1402-21$ & & \\
\hline IAC & $1399-8$ & IAC & $1402-22$ & & \\
\hline IAC & $1399-11$ & IAC & $1402-23$ & & \\
\hline IAC & $1399-12$ & IAC & $1402-24$ & & \\
\hline IAC & $1399-16$ & IAC & $1402-25$ & & \\
\hline IAC & $1399-17$ & IAC & $1402-26$ & & \\
\hline IAC & $1399-24$ & IAC & $1402-27$ & & \\
\hline IAC & 1399-25 & IAC & $1402-28$ & & \\
\hline \multirow[t]{2}{*}{ IAC } & $1399-26$ & IAC & $1402-29$ & & \\
\hline & & IAC & $1402-30$ & & \\
\hline
\end{tabular}


Pela classificação de CHEVALIER \& CHESNAIS (1941) os híbridos portadores de domácias enquadram-se nos seguintes tipos:

A - Domácias em "bolsas "

IAC $\quad 720-1$

IAC 1395-14

IAC $\quad 1402-9$

B - Domácias em "tufo de pêlos"

$\begin{array}{llll}\text { IAC } & 690-3 & \text { IAC } & 1399-26 \\ \text { IAC } & 717-1 & \text { IAC } & 1403-5 \\ \text { IAC } & 915-2 & \text { IAC } & 1403-7 \\ \text { IAC } & 960-11 & \text { IAC } & 1403-14\end{array}$

Variações deste tipo

a) Domácias em "pêlos exparsos"

$\begin{array}{lllr}\text { IAC } & 815-28 & \text { IAC } & 918-52 \\ \text { IAC } & 861-3 & \text { IAC } & 960-12 \\ \text { IAC } & 862-10 & \text { IAC } & 1120-5 \\ \text { IAC } & 866-39 & \text { IAC } & 1399-3\end{array}$

b) Domácias em "pêlos raros"

$\begin{array}{lcllll}\text { IAC } & 651-1 & \text { IAC } & 1398-42 & \text { IAC } & 1402-25 \\ \text { IAC } & 740-1 & \text { IAC } & 1399-16 & \text { IAC } & 1403-10 \\ \text { IAC } & 903-15 & \text { IAC } & 1402-8 & \text { IAC } & 1403-12 \\ \text { IAC } & 960-2 & \text { IAC } & 1402-16 & & \\ \text { IAC } & 1395-6 & \text { IAC } & 1402-23 & & \end{array}$

c) Domácias em “aglomerado de pêlos"

$\begin{array}{lcllll}\text { IAC } & 746-3 & \text { IAC } & 1399-17 & \text { IAC } & 1402-33 \\ \text { IAC } & 911-2 & \text { IAC } & 1402-12 & \text { IAC } & 1403-1 \\ \text { IAC } & 931-13 & \text { IAC } & 1402-18 & \text { IAC } & 1403-8 \\ \text { IAC } & 1398-26 & \text { IAC } & 1402-20 & \text { IAC } & 1403-13 \\ \text { IAC } & 1399-1 & \text { IAC } & 1402-26 & & \end{array}$




\section{RESULTADOS}

De um total de 120 híbridos examinados, encontramos domácias nas folhas de 47 deles.

As domácias ocorrem na face inferior da folha, ora na axila das nervuras, ora na confluência das nervuras com a inserção do pecíolo.

Observamos que ocorrem apenas os tipos em "tufo de pêlos" e "em bolsa" da classificação de CHEVALIER \& CHESNAIS (1941) .

As domácias do tipo "em tufo de pêlos", mostraram-se com "pêlos raros", "pêlos exparsos", "aglomerado de pêlos" e "tufo de pêlos" propriamente dito.

Pudemos constatar a presença de grande número de ácaros nas imediações e dentro das domácias, na totalidade brancos.

\section{SUMMARY}

\section{VI - OCCURENCE OF DOMATIA IN SPECIES AND HYBRIDS OF VITACEAE FAMILIAE}

Th1s paper deals with the ocurrence of domatia in hybrids of Vitaceae family. With this paper we finish a serie of works in according to a plan programmed about this subject.

The author found domatia in 47 of 120 hybrids studied.

The domatia found were of the types: "en touffe de poils" and "in pochette", according to CHEVALIER \& CHESNAIS (1941).

The leaves were examinated in both sides and in the junction of the blade with the petiole.

This paper is the 6 th and last work about this subject.

\section{LITERATURA CITADA}

ADAMOLI DE BARROS, Myrthes Apparecida, 1963. I Ocorrência de domácias em espécies e híbridos da família Vitaceae. Anais da E.S.A. "Luiz de Queiroz", vol. XX, pp. 241-255.

ADAMOLI DE BARROS, Myrthes Apparecida, 1966: II Ocorrência de domácias em espécies e híbridos da família Vitaceae. Anais da E.S.A. "Luiz de Queiroz", vol. XXIII, pp. 10-14.

ADAMOLI LE BARROS, Myrthes Apparecida, 1968. III Ocorrência de domácias em espécies e híbridos da família Vitaceae. Anais da E.S.A. "Luiz de Queiroz", vol. $\mathrm{XXV}, \mathrm{pp} .17-20$.

ADAMOLI DE BARROS, Myrthes Apparecida, 1975. IV Ocorrência de domácias em espécies e híbridos da família Vitaceae. Anais da E.S.A. "Luiz de Queiroz", vol. XXXII.

ADAMOLI DE BARROS, Myrthes Apparecida, 1976. V Ocorrência de domácias em cspécies e híbridos da família Vitaceae. Anais da E.S.A. "Luiz de Queiroz., vol. XXXIII.

CHEVALIER, AUGUSTE \& FRANCIS CHESNAIS, 1941. Botanique sur les domatics de feuilles de Juglandaceaes. Extraido de C.R. Academie des Sciencics 213, pp. 399-392. 
